\title{
Em busca da efetividade na administração pública: proposição de uma metodologia para design e implementação de serviços públicos no município de Florianópolis
}

\begin{abstract}
RESUMO
A abordagem do Novo Serviço Público e, mais recentemente, da Nova Governança Pública, chamam a atenção para a importância da efetividade dos serviços públicos, enfatizando o foco no cidadão e a coprodução do bem público como meios para o seu alcance. Entretanto, a proposição de serviços públicos efetivos tem sido um desafio para diversas organizações e esferas de governo. O contexto estudado, em Florianópolis, é o projeto Vida no Trânsito, vinculado ao Road Safety in 10 Countries Project, realizado por um consórcio internacional de parceiros. O estudo caracterizou-se como Pesquisa-Ação. Utilizou-se, na coleta de dados, o levantamento documental, a observação participante e o diário de pesquisa-ação. O resultado é a proposição de uma metodologia que visa apoiar o processo de design e implementação de serviços públicos municipais mais efetivos, a partir do intenso envolvimento dos stakeholders. Validada em campo e detalhadamente descrita no artigo, a metodologia é composta por seis etapas: Delimitação e Compreensão do Problema; Prospecção, Geração e Filtro de Soluçães; Elaboração do Protótipo; Concepção e Implementação do Projeto; Monitoramento e Avaliação; Redesign. Além do impacto gerado nos resultados locais do projeto, espera-se que ela possa ser adotada em outras secretarias da prefeitura de Florianópolis e nos demais municípios participantes do Projeto Vida no Trânsito. Além disso, o trabalho procura contribuir para o avanço teórico do ainda carente campo, que alia fundamentos do Novo Serviço Público, do Design de Serviços e do Gerenciamento de Projetos.
\end{abstract}

Palavras-chave: Efetividade. Novo Serviço Público. Design de Serviços. Projetos Públicos. Projeto Vida no Trânsito.

Grazielli Faria Zimmer Santos

graziellizimmer1@gmail.com Mestre em Administração Universidade do Estado de Santa Catarina - Brasil

Micheline Gaia Hoffmann michelinegaia@gmail.com Doutora em Engenharia de Produção Universidade do Estado de Santa Catarina - Brasil 


\section{INTRODUÇÃO}

Como resposta ao esgotamento das soluções protagonizadas pela Administração Tradicional, surgiu, nas últimas décadas do século XX, o modelo gerencial de gestão, também denominado Nova Administração Pública, consolidando a primeira reforma da Administração Pública. O mesmo apresenta como premissa básica, de acordo com Jackson (1994), o aumento da eficiência na gestão pública e, para isso, baseia-se na introdução de mecanismos de mercado e na adoção de ferramentas de gestão privada. Ainda, autores como Hood (1991), Pollitt (1990), Jackson (1994) e Denhardt e Denhardt (2000) destacam que o modelo gerencial está relacionado à gestão profissional, à introdução de medidas de desempenho, à maior transparência na relação custo/benefício, a mais competição entre fornecedores dos serviços públicos e à ênfase na qualidade do serviço prestado.

A abordagem do Novo Serviço Público (DENHARDT; DENHARDT, 2000) e, mais recentemente, da Nova Governança Pública (BEVIR, 2009; KISSLER; HEIDEMANN, 2006), posteriores ao modelo gerencial, chamam a atenção para a importância não apenas da eficiência dos serviços prestados, mas também da sua efetividade. Esta, associada por Cohen e Franco (2008) ao grau de correspondência entre objetivos e resultados, para ser alcançada requer o envolvimento dos cidadãos, de forma a possibilitar a identificação das reais necessidades dos usuários dos serviços ofertados, bem como o envolvimento de atores distintos na entrega e produção desses serviços.

Entretanto, identificar a necessidade do público-alvo de um determinado serviço público, bem como interagir com o mesmo, tem sido um desafio para diversas organizações e esferas de governo e particularmente para os Municípios, que por estarem inseridos em um contexto de contato e prestação direta de serviços às comunidades locais, são mais pressionados pela população e recebem um grande número de demandas por serviços públicos, sendo estas muitas vezes conflitantes entre si.

Como forma de lidar com a diversidade e complexidade associadas aos desafios do design e implantação de serviços públicos efetivos, o Governo Federal e mais 11 estados brasileiros criaram a carreira do Especialista em Políticas Públicas e Gestão Governamental. A carreira foi criada com o objetivo de fortalecer o nível estratégico de governo em suas capacidades de formulação, implantação e avaliação de políticas públicas e seus respectivos serviços, trazendo a possibilidade dos especialistas atuarem nas diversas áreas do governo.

Entretanto, existem limitações financeiras e políticas para a aplicação destas diretrizes no contexto dos Municípios, principalmente quando se trata de municípios de pequeno e médio porte. Além disso, percebe-se, neste contexto, a ausência de metodologias para design e implantação de serviços públicos capazes de auxiliar os gestores, sejam eles de carreira ou políticos, a dar expressão às necessidades dos cidadãos, envolvendo-os na concepção dos serviços dos quais são usuários. Nesse sentido, pode ser necessário aliar a criação da carreira do Especialista em Políticas Públicas e Gestão Governamental, com o desenvolvimento de metodologias específicas.

Ansell e Torfing (2014) discutem as limitações do paradigma da Nova Administração Pública na consecução de soluções para estes desafios e, ao discutir alternativas práticas para o contexto da Nova Governança Pública, destacam o potencial do design como referencial para metodologias mais promissoras, na medida em que ele tem na colaboração e no atendimento das necessidades do usuário os seus fundamentos essenciais. Além de inúmeros exemplos de experiências relatadas pelos autores, em Sunderland City Council(2008) encontra-se, também, a descrição de iniciativas pautadas nos pressupostos do design de serviços e do gerenciamento de projetos,implementadas com sucesso em municípios de países como a Inglaterra.

Neste cenário, este trabalho objetiva propor uma metodologia para o Design e a Implementação de Serviços Públicos efetivos no contexto do Projeto Vida no Trânsito no Município de Florianópolis, a partir dos pressupostos conceituais do Design de Serviços e do Gerenciamento de Projetos. Após a apresentação da realidade investigada, descreve-se o diagnóstico da situação problema e, a seguir, procede-se a análise e apresentação da metodologia proposta. Na sequência, descreve-se o processo de teste e validação da metodologia. Com base nos achados desta etapa, chega-se à proposição final.

\subsection{Objetivo geral}

O objetivo geral é propor uma metodologia para Design e Implementação de Serviços Públicos efetivos no contexto do Projeto Vida no Trânsito no Município de Florianópolis, a partir dos pressupostos conceituais do Design de Serviços e do Gerenciamento de Projetos.

\subsection{Objetivos específicos}

O presente trabalho tem como objetivos específicos:

- Realizar o diagnóstico da situação-problema e/ou oportunidade de intervenção no contexto e realidade investigada. 
- Verificar como as atribuições do Gerenciamento de Projetos poderiam de relacionar com as metodologias de Design de Serviços.

- Elaborar uma metodologia para Design e Implementação de Serviços Públicos efetivos.

- Testar/Validar a metodologia proposta.

\section{CONTEXTO E REALIDADE INVESTIGADA}

A violência no trânsito é responsável por aproximadamente 1.300 .000 mortes por ano, no mundo. Além das mortes, os desastres de trânsito geram 50.000.000 de feridos e um custo global de US\$ 518 bilhões/ano, o dobro do Produto Interno Bruto Nominal da Finlândia e mais de 585 vezes o de Guiné-Bissau (PEDEN et al., 2004).Em virtude disso, na sequência da publicação do Relatório Mundial sobre Prevenção de Lesões do Trânsito Rodoviário, em 2004, bem como a aprovação das recomendações deste relatório pela Assembleia Mundial da Saúde e pela Assembleia Geral da Organização das Nações Unidas - ONU, a Organização Mundial de Saúde - OMS aumentou o seu apoio a uma série de países para implementar projetos de segurança rodoviária.

Em 2007, foi recebido um financiamento da Bloomberg Family Foundation para começar os trabalhos de segurança rodoviária em dois países: México e Vietnã. Camboja foi adicionado mais tarde. Ganhos significativos foram feitos nestes três países, principalmente em termos de salvar vidas através da implementação e aplicação de legislações (capacete ou cinto de segurança) e por meio do desenvolvimento de capacidades.A partir destes resultados, em 2010, um consórcio de parceiros recebeu um financiamento da Bloomberg Family Foundation para ampliar a segurança rodoviária para 10 países de baixa ou média renda, desenvolvendo o projeto Road Safety in 10 Countries Project - RS10. O RS10 tem como objetivo subsidiar gestores nacionais no fortalecimento de políticas de prevenção de lesões e mortes no trânsito por meio da qualificação, planejamento, monitoramento, acompanhamento e avaliação das ações, no período entre 2010-2014.

No Brasil, o projeto foi lançado oficialmente em julho de 2010, com o nome de Projeto Vida no Trânsito. Tem como objetivo reduzir riscos associados ao trânsito e salvar vidas a partir de uma abordagem direcionada. O Projeto Vida no Trânsito é liderado por um grupo de trabalho interministerial, presidido pelo Ministério da Saúde e da OPAS/OMS escritório do Brasil e envolvendo representantes do Ministério das Cidades, Ministério dos Transportes, Ministério da Justiça, a Casa Civil, a Secretaria de Direitos Humanos, a Secretaria Nacional de Políticas sobre Drogas, a Polícia Rodoviária Federal, Departamento Nacional de Trânsito e Secretaria Nacional de Mobilidade Urbana e Transporte, bem como os Conselhos Nacionais de Secretários Estaduais de Saúde (Conass) e Municipais de Saúde (Conasems). A Organização Mundial de Saúde, a Global Road Safety Partnership e a Unidade Internacional de Pesquisa sobre Lesão da John Hopkins University são os parceiros internacionais do consórcio que irão fornecer orientação técnica e financiamento.

O Projeto piloto conta com cinco integrantes: Palmas/TO, Curitiba/PR, Campo Grande/MS, Belo Horizonte/ MG e Teresina/PI. Em dezembro de 2011, mais 22 municípios brasileiros, entre eles o município de Florianópolis, foram incluídos.

Florianópolis sofre, há algum tempo, com problemas relacionados ao trânsito. Por ano, durante o deslocamento de pessoas no município, o registro de mortes chega a quase uma centena. A taxa de mortalidade relacionada ao trânsito é quase $30 \%$ superior à das maiores capitais do Sul-Sudeste, como São Paulo e Rio de Janeiro; e quase 500\% maior que a de países como a Holanda, Noruega e Reino Unido (WAISELFISZ, 2013). Além disso, este município é a capital do país onde mais se dirige e consome bebidas alcoólicas (BRASIL, 2013).

Em Florianópolis, a implementação e o acompanhamento do projeto está, atualmente, sob responsabilidade da Rede Vida no Trânsito. É neste cenário do Projeto Vida no Trânsito que se concentra o foco de análise do presente trabalho.

\section{DIAGNÓSTICO DA SITUAÇÃO-PROBLEMA}

Para realizar o diagnóstico utilizou-se, em uma primeira etapa, a análise documental, tendo como finalidade conhecer e compreender o período histórico e social em que se desenvolveu o Projeto Vida no Trânsito em Florianópolis. Para isso, foram analisadas as atas das reuniões da Comissão Intersetorial de Redução da Morbimortalidade por Acidentes de Trânsito, atualmente denominada Rede Vida no Trânsito, bem como o relatório World Report on Road Traffic Injury Prevention (PEDEN et al., 2004). Esta primeira etapa teve como objetivo o levantamento de dados do período de inicialização do Projeto Vida no Trânsito em Florianópolis até outubro de 2013, visando à compreensão do contexto que antecedeu a adoção da metodologia de trabalho atualmente utilizada pela Rede Vida no Trânsito.

A segunda etapa do diagnóstico, por sua vez, teve como objetivo compreender a Estratégia de Proatividade e Parceria - EPP (CARDITA; DI PIETRO, 2010), metodologia adotada para a condução dos trabalhos da Rede Vida no Trânsito a partir de dezembro de 2013, bem como a estrutura de trabalho decorrente da metodologia 
adotada. Destaca-se, para o levantamento de dados da segunda etapa, a utilização da Observação Participante (GODOY, 2006). Nesse sentido, acompanhou-se as reuniões ampliadas da Rede Vida no Trânsito no mês de dezembro de 2013 e janeiro e fevereiro de 2014.

Cumpre notar que, nessa etapa da pesquisa, deu-se ênfase a utilização da primeira fase do processo de observação participante, apresentada por Leininger (1985) como Observação Primária ou Inicial, que se caracteriza pelo observar e o ouvir, com vistas à obtenção de ampla visão do contexto estudado. Trata-se, assim, de um passo anterior ao envolvimento do pesquisador com uma situação específica daquele contexto, ou seja, a situação-problema a ser trabalhada. O foco na fase de Observação Primária ou Inicial se deu em virtude de que as reuniões tiveram como principal objetivo a apresentação detalhada do desenvolvimento da Estratégia de Proatividade e Parceria - EPP. Assim, o acompanhamento destas reuniões teve como justificativa a compreensão deste processo.

Complementarmente à Observação Primária ou Inicial, utilizou-se a análise documental, em específico do documento da Estratégia de Proatividade e Parceria - EPP (CARDITA; DI PIETRO, 2010).

Como ferramenta para a análise da situação atual da Rede Vida no Trânsito, utilizou-se a adaptação do modelo de avaliação organizacional desenvolvido por Scott (2003), partindo da premissa de que a Rede Vida no Trânsito, enquanto rede, pode ser entendida também como uma organização sob a ótica dos sistemas abertos. A ferramenta proposta por Scott (2003) para análise organizacional e adaptada nesse trabalho para análise de redes, apresenta cinco elementos inter-relacionados e não hierarquizados para a análise, os quais embasaram a coleta de dados do diagnóstico: a) participantes; b) objetivos; c) estrutura social; d) tecnologias; e) ambiente.

O Quadro 1 apresenta como foram distribuídos os dados levantados por elementos de análise, os quais trouxeram à luz a situação-problema a ser trabalhada.

Quadro 1 - Dados levantados por elemento de análise

\begin{tabular}{|c|c|}
\hline Elementos de análise & \multicolumn{1}{c|}{ Dados levantados } \\
\hline Participantes & * Instituições participantes do Projeto Vida no Trânsito; \\
$*$ Média de participação;
\end{tabular}

Fonte: Produção do próprio autor (2014).

Destaca-se que todos os elementos de análise foram trabalhados em sua relação com o ambiente externo.

\subsection{Participantes}

O Projeto Vida no Trânsito, implantado em Florianópolis em 2011, é desenvolvido por uma rede de atores públicos, privados e da sociedade civil, que formaram, inicialmente, a Comissão Intersetorial de Redução da Morbimortalidade por Acidentes de Trânsito, denominada atualmente Rede Vida no Trânsito.

Observa-se que, apesar da grande quantidade de entidades que assinaram a Carta de Adesão à Comissão Intersetorial de Redução da Morbimortalidade por Acidentes de Trânsito, a participação média nas reuniões ampliadas até outubro de 2013 era de 10 pessoas, variando de 4 a 16. A baixa participação, bem como a concentração desta entre técnicos e membros da média gerência, principalmente ligados à Secretaria Municipal de Saúde, evidencia a dificuldade de envolvimento dos cidadãos-usuários, ou seja, dos atores que de fato vivenciam o problema e que possuem conhecimento das principais necessidades a serem trabalhadas. Em relação a este ponto, é válido observar que autores como UNICEF ([20--?]), Cotta (1998), Cohen e Franco (2008), European Comission (2005) e Kellogg Foundation (1998), ao discutirem a questão da avaliação de projetos e programas públicos, destacam que as principais dificuldades para alcançar resultados efetivos estão ligadas à formulação de planos de forma inconsistente frente às necessidades dos usuários. Isso ressalta a importância de se promover mecanismos de mapeamento e de fomento ao envolvimento destes atores, o que não foi identificado no caso em análise. 


\subsection{Objetivos}

O Projeto Vida no Trânsito tem, no Brasil, o objetivo de reduzir riscos associados ao trânsito e salvar vidas a partir de uma abordagem direcionada.

Com base nisso, no final de 2012, a Comissão Intersetorial de Redução da Morbimortalidade por Acidentes de Trânsito realizou um planejamento rudimentar, estabelecendo os seguintes objetivos específicos para 2013: Realização de contatos para confirmação de indicação de nomes; Divulgação na mídia; Apresentação do Projeto Vida no Trânsito para: Conselho Municipal de Saúde, Prefeito, Câmara de Vereadores e Governador do Estado; Providências para elaboração e produção de texto para material informativo; Implantação do sistema de informação e análise de dados de acidentes fatais do último trimestre de 2012; Análise inicial de dados existentes nos bancos de dados da Polícia Rodoviárias Estadual, SAMU, Corpo de Bombeiros, IML, Vigilância Epidemiológica de Florianópolis, Sistema de Mortalidade de Autorizações de Internação Hospitalar; Estudo do Código de Trânsito para definir ações educativas e fiscalizatórias; Encaminhamento de datas relativas ao trânsito para definição e proposta de eventos alusivos; Levantamento de projetos existentes na atualidade, referentes às vias, rodoviárias, inspeção veicular e projetos de mobilidade; Estudos de ações prioritárias de fiscalização, baseados em dados de mortalidade e internação de vítimas de acidentes de trânsito no ano de 2012 associados aos fatores de risco; Definição das prioridades considerando análise e carta do Fórum da Sociedade Brasileira de Ortopedia e Traumatologia e Advocacy junto ao Legislativo Municipal e Estadual.

Porém, o Planejamento não foi seguido e até outubro de 2013 as parcerias para o desenvolvimento do sistema de informação e produção das informações ainda não tinham sido firmadas, as áreas de intervenção (fatores de risco) não tinham sido definidas e os programas com seus respectivos projetos e ações não haviam sido desenhados. Até outubro de 2013, as ações realizadas pela Comissão foram pontuais e não relacionadas aos objetivos específicos preliminarmente definidos, restringindo-se: as apresentações dos sistemas de informação entre as organizações participantes, para um nivelamento do conhecimento dos diversos sistemas de informação relacionados ao trânsito em Florianópolis; ao esforço para a manutenção da rede, realizado pela coordenação executiva do Projeto, através da construção e divulgação de calendário de reuniões e de comunicações frequentes por meio eletrônico com os membros da Comissão; a condução de reuniões, confecção e distribuição de material educativo e ações não sistemáticas de educação no trânsito em eventos e em datas alusivas ao trânsito, como a Semana Nacional de Trânsito. Além disso, é válido observar que não houve um acompanhamento das mesmas e, portanto, a efetividade delas não foi mensurada.

Dessa forma, preceitos teóricos vistos em Armani (2004), Wholey, Hatry e Newcomer (2004), Cohen e Franco (2008), Kellogg Foundation(1998) e European Comission (2005), que enfatizam a importância do acompanhamento de programas e ações, não foram seguidos.

\subsection{Tecnologias}

As ações do Projeto Vida no Trânsito, nas cinco capitais piloto, tiveram sua execução prevista em duas etapas. A primeira teve início em 2011 e foi até 2012. Entre as atividades, estavam a definição dos alvos a serem atingidos, a criação do Plano de Ações e a busca pelas parcerias para a reversão dos índices de vítimas graves e mortes em acidentes.

Já a segunda, etapa iniciou-se em 2013 e foi até o final de 2014. Antes disso, as Capitais participantes deveriam colocar em prática experiências relacionadas ao trânsito de forma que outras cidades brasileiras pudessem reproduzi-las no dia a dia. No prazo de dois anos, seriam necessários o planejamento e a implementação das ações que reduzissem as lesões e mortes provocadas pelo trânsito, além da estruturação de mecanismos de monitoramento e avaliação das atividades e dos resultados alcançados entre os municípios selecionados.

O norteamento do projeto na primeira etapa foi dado pelos fatores de risco prioritários estabelecidos pelas cidades. Para cada tema definido, as instituições elaboraram os planos a serem executados ao longo dos anos. Para os municípios, a estratégia proposta pelo Ministério da Saúde foi dividida da seguinte forma: (1) Estruturar a Comissão Municipal do Projeto Vida no Trânsito; (2) Elaborar o Plano Municipal (foco inicial: capital); (3) Estruturar o comitê gestor da informação sobre mortalidade, morbidade e acidentalidade para produção de análises de situação e tendências e qualificação dos dados; (4) Analisar e qualificar os dados sobre mortalidade e feridos graves (internações) no trânsito cruzando com outras informações (BO, SAMU, outros); (5) Definir os fatores de risco e/ou grupo de vítimas/população vulnerável; (6) Promover a capacitação das equipes locais e; (7) Desenhar os programas e projetos. Esta estratégia reflete processos associados a boas práticas em planejamento e gerenciamento de projetos públicos vistas em autores como Armani (2004), Bolay (1993), Cotta (1998), Cohen e Franco (2008), Kellogg Foundation (1998) e European Comission (2005).

Como forma de orientar os trabalhos da Comissão, atualmente denominada Rede Vida no Trânsito, adotou-se, em dezembro de 2013, uma metodologia denominada Estratégia de Proatividade e Parceria - EPP 
(CARDITA; DI PIETRO, 2010). Essa metodologia foi criada pela Global Road Safety Partnership especificamente para abordar as questões de segurança no trânsito e foi adotada por diversas outras cidades que trabalham o projeto Vida no Trânsito no Brasil. Sua adoção visou não apenas uma adequação às diretrizes ministeriais, mas também dispor de uma ferramenta para apoiar a estruturação das ações a serem propostas, de modo que as mesmas pudessem se tornar efetivas e sustentáveis.

Seis etapas compõem a implementação da EPP. São elas: (1) Formação de Parcerias; (2) Coleta, Gestão e Análise dos Dados; (3) Ações Integradas de Segurança Viária (PPP - processo de proatividade e parceria); (4) Monitoramento de Desempenho, Avaliação e Reconhecimento; (5) Revisão Geral Anual e (6) Expansão e Renovação.

A formação de parcerias, primeira etapa, envolve a reunião de parceiros-chave da EPP (grupos e organizações de liderança), os quais assumem o compromisso/acordo público para tomar ações de segurança no trânsito. Na coleta, gestão e análise dos dados são trabalhados os dados confiáveis das instituições envolvidas, de modo a obter um diagnóstico preciso sobre a situação dos acidentes fatais e graves de trânsito. Na terceira etapa, denominada Ações Integradas de Segurança Viária, devem ser desenhados os programas e seus respectivos projetos e ações, bem como estabelecidos os indicadores para monitoramento dos mesmos. A quarta etapa - Monitoramento do Desempenho, Avaliação e Reconhecimento - os objetivos e indicadores previamente estabelecidos são monitorados periodicamente. Na quinta etapa é feita a Revisão Geral Anual das ações, envolvendo todos os atores envolvidos, seja de forma direta ou indireta. A sexta e última etapa, por fim, denominada Expansão e Renovação, estabelece que, por ser um processo dinâmico de melhoria contínua, é necessário que sejam feitas reflexões e melhorias todos os anos, de modo a renovar e expandir a estratégia.

Entretanto, embora a EPP apresente, na terceira etapa, a necessidade de desenhar os programas e seus projetos, com seus respectivos serviços e ações, a mesma não estabelece os passos necessários para que o processo ocorra de forma efetiva. Não há uma metodologia que auxilie os gestores a desenharem e implantarem novos serviços que de fato atendam às necessidades identificadas e enfrentadas pelos atores envolvidos, denominados aqui cidadãos-usuários. Sendo assim, a pesquisa parte da seguinte situaçãoproblema: "A falta de uma metodologia específica que auxilie o Município de Florianópolis, especificamente a Rede Vida no Trânsito, no Design e Implantação de Serviços Públicos efetivos e voltados às necessidades dos cidadãos-usuários".

Ainda em relação à EPP (CARDITA; DI PIETRO, 2010) não são apresentados, neste diagnóstico, os resultados de sua utilização, tendo em vista que o intervalo de tempo ora analisado vai até a adoção da EPP por parte da Rede Vida no Trânsito. Apenas a mudança na estrutura de trabalho da Rede, decorrente da utilização da EPP, é demonstrada na seção a seguir.

\subsection{Estrutura Social}

Para o desenvolvimento dos trabalhos em Florianópolis, a Comissão Intersetorial de Redução da Morbimortalidade por Acidentes de Transito criou, em julho de 2012, subgrupos de trabalho a partir dos cinco pilares do Plano Decenal: fortalecimento da gestão da segurança no trânsito; infraestrutura viária adequada; segurança veicular; comportamento e segurança dos usuários e atendimento ao trauma, assistência préhospitalar, hospitalar e à reabilitação.

Foram constituídas, então, quatro subcomissões: a Subcomissão de Gestão da Informação; Subcomissão de Segurança Veicular e Viária, Fiscalização e Mobilidade; Subcomissão de Educação, Comportamento e Segurança no Trânsito e Subcomissão de Assistência ao Trauma Pré-hospitalar, Hospitalar e de Reabilitação. Estas comissões foram compostas, por afinidade ao tema, com representantes do poder público, iniciativa privada e sociedade civil organizada. Além das Subcomissões, foi criada uma Coordenação Executiva, que é realizada pela Secretaria Municipal de Saúde, e uma Coordenação Geral, assumida pelo Instituto de Planejamento Urbano de Florianópolis. Até outubro de 2013, apenas as Subcomissões de Gestão da Informação e de Educação, Comportamento e Segurança no Trânsito estavam atuando. Entretanto, percebeuse que Florianópolis, apesar de já ter estruturado sua Comissão e uma Subcomissão focada na informação, não seguia, até outubro de 2013, a proposta ministerial para a condução dos trabalhos.

A formalização na Comissão também era baixa, não havendo um regimento interno, apesar do desejo pela sua construção já aparecer em atas de reuniões há mais de 1 ano. No período, o seu principal instrumento gerencial eram as reuniões, tantos das Subcomissões quanto da Comissão Ampliada, com todos os participantes, onde os compromissos eram pactuados e, posteriormente, relatados em atas.

A partir da adoção da EPP em Florianópolis, percebeu-se, principalmente em virtude dos componentes da Formação de Parcerias acima apresentados, que a nomeação de uma Comissão enquanto instrumento de formalização da parceria entre os atores envolvidos no Projeto Vida no Trânsito, enrijecia o processo, uma vez que a mesma listava de forma fixa os parceiros que fariam parte do acompanhamento do Projeto, dificultando a entrada de novos atores. Além disso, entendeu-se que a Secretaria de Saúde, responsável pela 
Portaria de criação da Comissão Intersetorial de Redução da Morbimortalidade por Acidentes de Trânsito, não possuía legitimidade para controle dos parceiros e, portanto, uma Portaria assinada pelo Secretário Municipal de Saúde não seria a melhor forma de formalização das parcerias. Sendo assim, na reunião ampliada de janeiro de 2014, foi criado um Grupo de Trabalho para a Elaboração do Regimento Interno, o qual também discutiria que formato esse grupo, até então constituído como Comissão, assumiria e, consequentemente, de que forma seriam formalizadas as parcerias com os atores envolvidos. Após as discussões, optou-se pela adoção do formato de rede, com a utilização dos Acordos de Parceria, propostos pela EPP, como instrumento de formalização das parcerias com os diversos atores envolvidos no processo.

Ainda em janeiro de 2014, na reunião ampliada do grupo, a partir da identificação das áreas de intervenção dos programas - motociclistas, velocidade e beber e dirigir - as Subcomissões, anteriormente criadas para desenvolvimento dos trabalhos, foram substituídas pelos Grupos de Trabalhos - GT. Os mesmos têm como objetivo desenvolver programas, projetos e atividades necessárias à concretização dos objetivos definidos pelo planejamento da Rede Vida no Trânsito. Dessa forma, criou-se o Grupo de Informação, responsável pela análise dos dados (etapa 2), bem como o GT Motociclistas, GT Velocidade e GT Beber e Dirigir, responsáveis pelo desenvolvimento dos programas e seus respectivos serviços. Posteriormente, ainda foi criado o GT de Comunicação Social, responsável por promover a disseminação de informações para agregar os membros da rede e colocar o problema do trânsito na agenda social e política.

O lançamento oficial da Rede Vida no Trânsito ocorreu no dia 11 de junho de 2014, formalizando os trabalhos desenvolvidos a partir de janeiro de 2014 e oficializando as parcerias com os atores por meio da assinatura dos Acordos de Parceria.

\section{ANÁLISE DA SITUAÇÃO-PROBLEMA E APRESENTAÇÃO DA METODOLOGIA PROPOSTA}

Osborne, Radnor e Nasi (2013), ao discutir o processo de design de um serviço público, destacam que compreender as expectativas e necessidades dos usuários é fundamental para o alcance de sua satisfação. Esta experiência afeta profundamente a efetividade e o impacto do serviço proposto. Da mesma forma, ao abordar metodologias de design de serviços, Hollins e Hollins (1991) destacam a compreensão das necessidades dos cidadãos como a chave do sucesso. Entretanto, entende-se que a compreensão das necessidades e expectativas dos usuários do serviço pressupõe a interação dos gestores com os diversos atores envolvidos, o que coloca em evidência uma mudança no posicionamento dos gestores públicos e das técnicas utilizadas para o design dos serviços. Mais do que definir as regras e controlar a sua aplicação ou construir isoladamente os serviços, cabe aos Municípios favorecer interações em torno de interesses comuns de modo que, de maneira conjunta, seja possível identificar o que de fato constitui o interesse ou problema público e construir o serviço público a ser ofertado.

No contexto desse trabalho, é importante observar que o processo de criação e implementação de serviços públicos segue lógica similar à gestão de projetos. Por constituir um esforço temporário, dirigido a cumprir metas estabelecidas de custo e tempo, o design e a implantação de um serviço público efetivo podem ser gerenciados nas organizações como projetos. Armani (2004) corrobora essa ideia, afirmando que um projeto é a ferramenta mais adequada para a implantação de uma política pública e seus respectivos serviços, bem como para a implantação de um protótipo decorrente do processo de design, tendo em vista que o mesmo traz este protótipo para a realidade na forma de unidades de intervenção concretas. Destaca-se ainda que, aqui, na maior parte das ações associadas à implantação de um serviço, o ZOPP (BOLAY, 1993) foi utilizado como metodologia. Sendo assim, a metodologia proposta alia os pressupostos conceituais do Design de Serviços e do Gerenciamento de Projetos e é apresentada como alternativa de intervenção para a problemática anteriormente descrita. Ela tem como objetivo auxiliar no design e implantação de serviços públicos efetivos.

A metodologia é constituída por seis etapas, a saber: (1) Delimitação e Compreensão do Problema; (2) Prospecção, Geração e Filtro de Soluções; (3) Elaboração do Protótipo; (4) Concepção e Implementação do Projeto; (5) Monitoramento e Avaliação e (6) Redesign.

A primeira etapa consiste na Delimitação e Compreensão do Problema, abordada por Hollins e Hollins (1991) como o início do processo de design, uma vez que traz as informações que são fundamentais e baseiam todo o restante do processo. A mesma possui duas subdivisões: Delimitação do Problema e Compreensão do Problema.

A primeira subdivisão, denominada Delimitação do Problema, envolve primeiramente a definição do problema central, o qual, de acordo com o ZOPP (BOLAY, 1993), deve focar com exatidão o cerne da problemática. A partir desta definição, são mapeados os atores envolvidos com o problema levantado. Para isso, são enumerados de maneira não sistemática todos os grupos de interesse ou instituições presentes na região e suscetíveis de exercer certa influência sobre o problema central ou de ser afetados pelo mesmo. Estes grupos podem, de acordo com o ZOPP (BOLAY, 1993) ser classificados como participantes e não participantes, sendo 
que os participantes devem ser incorporados ao grupo de trabalho, de modo que seja possível compreender as necessidades do ponto de vista dos atores que vivenciam o problema (MOZOTA, 2003; BROWN, 2008). Além disso, Armani (2004) destaca que a participação de todos os atores relevantes é de fundamental importância para aumentar as chances de chegar-se aos fins propostos. Sendo assim, com o grupo de trabalho consolidado, estabelece-se o objetivo geral a ser alcançado com a implantação dos serviços a serem propostos. No caso de programas que envolvem inúmeros serviços, estabelece-se o foco do programa, ou seja, o objetivo geral a ser monitorado. Segundo Armani (2004), o objetivo geral expressa o impacto mais geral a ser perseguido, além dos efeitos produzidos para os seus beneficiários diretos e/ou das organizações envolvidas. Por fim, a partir da definição do objetivo geral, deve ser estabelecido um indicador respectivo, bem como a meta desejável e o meio de verificação, que permitirá que os dados associados ao cumprimento da meta sejam acessados e auferidos.

A segunda subdivisão da primeira etapa, por sua vez, denominada Compreensão do Problema, se inicia com a análise de causas e efeitos do problema central. Para a análise de causas e efeitos, as causas principais e imediatas do problema central devem ser dispostas paralelamente por baixo do mesmo, umas ao lado das outras e os efeitos principais e imediatos devem ser colocados paralelamente, por cima do problema central. $\mathrm{O}$ resultado final obtido pode ser chamado de Árvore de Problemas e deve refletir de forma detalhada as causas e efeitos do problema central. Entretanto, após a elaboração da árvore principal, deve-se elaborar a Árvore de Problemas com governabilidade, ou seja, selecionam-se apenas as causas em que o grupo de trabalho possui os recursos necessários para atuar. Esta segunda árvore será utilizada como árvore de trabalho e como base para a proposição de ações nas etapas subsequentes. Finalizando a primeira etapa, com base nas causas e efeitos governáveis construídos, são delimitados os indicadores intermediários, por meio dos quais serão mensurados os avanços mais pontuais ao longo da implementação das ações (COTTA, 1998).

A segunda etapa parte dos dados levantados na primeira e consiste na Prospecção, Geração e Filtro de Soluções. É nesta fase que surgem os serviços a serem prototipados e implantados. Brown (2008) descreve esse momento como a idealização, que abrange o processo de gerar e desenvolver as ideias. Esta primeira etapa possui 3 subdivisões - Prospecção, Geração de Soluções e Filtro de Soluções.

A Prospecção tem início com a identificação dos serviços/projetos que trabalham ou já trabalharam os problemas identificados e suas causas na região. Além disso, também deve-se buscar ações já realizadas em outras localidades relacionadas à temática e que podem ser adaptadas ao caso concreto (HOLLINS; HOLLINS, 1991). Feito isso, delimitam-se os pontos fortes e fracos dos serviços identificados, de modo a analisá-los de forma crítica.

Após a análise dos pontos fortes e fracos dos serviços levantados, parte-se para a Geração de Soluções, na qual primeiramente se analisa como os serviços existentes podem ser melhorados. Em relação a este ponto, Hollins e Hollins (1991) chamam atenção para o fato de que as coisas não devem ser feitas sempre da mesma maneira como foram feitas no passado e, por isso, é importante analisar os serviços existentes para ver se existem outras maneiras melhores de ofertar o mesmo (MOZOTA, 2003). Posteriormente, são identificados novos serviços ou ações que podem ser criados. Mozota (2003) destaca a possibilidade de se ter como resultado do processo de design de um serviço uma inovação de ruptura, que por sua vez, em alguns contextos, pode ser vital para a efetividade do serviço a ser ofertado. O autor aponta que em determinadas situações o design incremental não se mostra efetivo.

Concluída a Geração de Soluções, passa-se para o Filtro de Soluções, última subdivisão da segunda etapa, composta pela análise externa e interna.

Para a análise externa do Filtro de Soluções, propõe-se a utilização da análise de viabilidade apresentada por lida (1993), ao trabalhar o Planejamento Estratégico Situacional. A análise de viabilidade proposta pelo autor incorpora três variáveis: operações, recursos e atores. Primeiramente, é necessário listar as operações, ou seja, as ações capazes de modificar o estado de algum nó crítico. Neste caso, as ações propostas no momento de Geração de Soluções se configuram como as operações a serem analisadas. A seguir, listam-se os recursos necessários para realizar as operações. É válido observar que estes nem sempre estão relacionados a bens materiais ou monetários. Em alguns casos, podem ser determinadas habilidades, liderança, influência política etc. Listam-se, ainda, os atores que detêm algum tipo de controle sobre esses recursos e que, por isso, podem influenciar na solução do problema.

A partir dessas definições, constroem-se três matrizes, relacionando as variáveis acima entre si. A primeira delas relaciona as variáveis "atores" e "operações" e é denominada Matriz de Motivações. A mesma tem como objetivo analisar de que forma cada um dos atores se posiciona frente às operações propostas, de maneira negativa ou positiva. A segunda matriz é denominada Matriz de Recursos Necessários e relaciona às variáveis "operações" e "recursos", identificando quais recursos são necessários para cada uma das operações propostas. Por fim, constrói-se a Matriz de Controle dos Recursos, a qual relaciona as variáveis "recursos" e "atores", tendo como objetivo avaliar as intensidades relativas dos controles que os atores exercem sobre os recursos necessários (IIDA, 1993). 
A análise de viabilidade (externa) é feita a partir das três matrizes acima mencionadas. lida (1993) destaca que, em geral, nem todas as operações são viáveis na situação inicial, pois podem existir atores que se opõem a determinadas operações, controlando recursos em montante superior aos dos atores que lhe são favoráveis. No balanço geral, as operações viáveis serão aquelas em que a maior parte dos atores favoráveis detém o maior montante dos recursos necessários.

Feita a análise externa e determinadas as operações (soluções) viáveis, parte-se para a análise interna. Para isso, a metodologia propõe uma Matriz de Prioridades. A matriz tem o intuito de sintetizar as informações internas relevantes à avaliação das ideias, servindo também de checklist para apresentação dos procedimentos necessários a sua correta avaliação. Cumpre destacar que, neste momento, apenas são avaliadas as ideias já consideradas viáveis na avaliação externa.

A metodologia adotada na elaboração da matriz corresponde ao modelo de matriz de priorização de projetos, que torna as decisões baseadas não somente em uma simples análise financeira, mas em uma avaliação mais completa, onde devem ser considerados diversos critérios gerais que poderão dar maior sustentação à tomada de decisão (DAYCHOUM, 2010). A composição da matriz incorpora fatores que são subdivididos em critérios a serem avaliados. No processo de avaliação, os fatores são valorizados através da imposição de "pesos" que, somados, devem totalizar 1,0. A determinação destes "pesos" deve considerar os fatores mais determinantes na escolha dos projetos. Cada critério que compõem os fatores, deve ser avaliado através de pontuação, com variação de 1 a 5, que multiplicados pelo peso definido nos fatores, resulta na pontuação do critério. Na composição da matriz desenvolvida, foram adotados os seguintes fatores: políticos, financeiros, técnicos e diversos que se subdividem em critérios específicos. O fator político apresenta como critérios: a viabilidade da ideia, externalidades negativas, externalidades positivas e tempo de maturação. Já o fator financeiro leva em conta os seguintes critérios: recursos previstos, captação de recursos e probabilidade de aditivos. O fator técnico, por sua vez, apresenta como critérios a existência da documentação necessária, a complexidade da ideia e o tempo de elaboração do projeto. Por fim, o fator diversos abrange como critérios: o tempo de execução do projeto, a congruência com o objetivo geral e o nível de resolução do problema. Observa-se, entretanto, que os critérios estabelecidos podem ser alterados de acordo com as necessidades específicas dos grupos de trabalho.

Ao final do preenchimento da matriz, que aponta, por meio da pontuação, para as ideias com maior viabilidade de execução no que diz respeito aos fatores internos, têm-se as ideias já priorizadas, as quais passam para a etapa de elaboração do protótipo.

A terceira etapa da metodologia proposta consiste na Elaboração do Protótipo. Ao trabalharem o processo de design, tanto de produtos quanto de serviços, autores como Brown (2008), Mozota (2003), Hollins e Hollins (1991), Moritz (2005), Siodmok (2008) e Lockwood (2010) destacam a importância de construção do protótipo antes do momento de implantação de ideia, tendo em vista que é o momento em que as ideias até agora abstratas ganham um conteúdo mais denso. Além disso, através do protótipo é possível estabelecer o escopo do serviço a ser implantado, para o qual todo o projeto será elaborado. Como forma de auxiliar na elaboração do protótipo, a presente metodologia propõe a utilização do 5W2H (OLIVEIRA, 1996), uma vez que a ferramenta apresenta os pontos principais a serem analisados no protótipo: o que será feito, quem será responsável pela execução, quando o serviço será implantado, onde as ações serão realizadas, por que o serviço proposto é necessário (justificativa) e como se dará o seu fornecimento.

A etapa de Concepção e Implementação do Projeto consiste na quarta etapa da metodologia. Aqui, o serviço anteriormente prototipado e, portanto, com o escopo já definido, entra no processo de implantação. Para a elaboração do projeto parte-se da construção da Matriz de Planejamento do Projeto (BOLAY, 1993), na qual são descritos os objetivos (objetivo superior e objetivo do projeto), os resultados esperados, as atividades necessárias para o alcance dos resultados previstos, bem como os indicadores e suas respectivas fontes de comprovação. Observa-se, aqui, que os indicadores apresentados ao longo da matriz dos projetos podem ser de impacto, de efetividade, de desempenho ou indicadores operacionais (ARMANI, 2004), dependendo do foco de avaliação necessário. A partir da Matriz de Planejamento do Projeto são delimitadas as suposições importantes, ou seja, examina-se se as atividades conduzem diretamente aos resultados respectivos ou se um evento externo adicional tem forçosamente que acontecer. Delimitadas as suposições importantes, propõe-se a realização da análise de relevância e riscos das suposições adotadas. Posteriormente, a partir da lista de atividades construída na Matriz de Planejamento do Projeto, parte-se para a elaboração do cronograma, o qual é calculado com base na estimativa de tempo estabelecida e na rede de dependências (MENEZES, 2009). Após a construção do cronograma, passa-se para a análise e determinação dos custos do projeto, de seu orçamento. A estimativa de custos do projeto, de acordo com Menezes (2009), requer a identificação e determinação dos recursos físicos - pessoas, equipamentos, materiais e financeiros - e suas respectivas quantidades necessárias para executar as atividades do projeto. Propõe-se ainda que o projeto desenvolva uma estratégia de comunicação, de modo que todas as partes interessadas, as quais são levantadas na primeira etapa da metodologia sejam envolvidas ao longo da implantação do serviço desenvolvido. 
Estabelecidos todos os pontos acima mencionados, inicia-se a implementação do projeto, a qual deve ser monitorada e avaliada de forma sistemática. Gido e Clements (2007) observam que o processo de controle de um projeto envolve a coleta de dados regular sobre o desempenho do mesmo, a comparação do desempenho real com o planejado e a aplicação de ações corretivas caso necessário. Por fim, após a execução, o projeto entra em fase de encerramento. Nesta fase, além da entrega dos resultados, estão os relatórios de prestação de contas ao financiador externo ou à própria organização, os relatórios técnicos, os de avaliação e o de lições aprendidas.

A quinta etapa da metodologia consiste no Monitoramento e Avaliação do conjunto de serviços propostos. Este processo avaliativo tem como finalidade verificar a efetividade do programa frente ao objetivo maior, o qual foi estabelecido na primeira etapa da metodologia. Para isso, é necessário mensurar a evolução dos indicadores intermediários estabelecidos com bases nas causas e efeitos governáveis, bem como a evolução do indicador desenvolvido para o objetivo geral do programa. Por fim, a partir dos resultados apresentados pela etapa de Monitoramento e Avaliação, parte-se para o Redesign, que consiste na sexta e última etapa da metodologia. Aqui, o ciclo proposto pela metodologia é reiniciado, agora com a realimentação das informações.

\section{TESTE E VALIDAÇÃO DA METODOLOGIA PROPOSTA}

Para a fase de teste/validação, foram utilizados como instrumentos de coleta de dados material documental e o diário de pesquisa-ação. Este último, descreve as reuniões realizadas com o Grupo de Trabalho selecionado para a intervenção proposta: o grupo responsável pela área de intervenção "motociclistas" (GT Motociclistas). Estas reuniões tiverem como objetivo o teste e aprimoramento da metodologia desenvolvida na fase de planejamento. Para que o teste fosse operacionalizado, auxiliou-se o GT Motociclistas no desenvolvimento de um programa e de seus respectivos serviços e projetos. Assim, essa fase da pesquisa também teve uma contribuição prática e imediata para a organização.

Observa-se, que, para a fase de teste/validação, a metodologia proposta foi dividida em duas grandes fases: Design e Implementação. Optou-se pelo teste/validação apenas da fase de Design. Este corte se deu em virtude, primeiramente, do tempo disponível para a realização da pesquisa. Além disso, a fase de Implementação tem como base os preceitos teóricos e as ferramentas de Gerenciamento de Projetos, área de conhecimento já consolidada. Diversas pesquisas, como as de Armani (2004), Cohen e Franco (2008), Cotta (1998), Doloi (2011), Gido e Clements (2007) e Tulip (1983), utilizadas neste trabalho, já apresentam os resultados de sua utilização. No que diz respeito à fase de Design, entretanto, principalmente no formato desenvolvido neste trabalho (que une ferramental de diferentes áreas de conhecimento), percebeu-se a necessidade de validação. Nesse contexto, julga-se relevante a validação na medida em que se propôs um formato novo, distinto daqueles apresentados por pesquisas relacionadas ao Design de Serviços ou Design Thinking e, portanto, não testado anteriormente.

Os resultados da fase de Teste/Validação são descritos a seguir, seguindo a sequência das etapas que compõem a metodologia proposta.

\subsection{Delimitação e Compreensão do Problema}

A primeira subdivisão da primeira etapa, a Delimitação do Problema, tem início com a Definição do Problema Central. Tendo em vista que o GT Motociclistas tem como foco a problemática relacionada ao número de mortes e feridos graves, especificamente no que diz respeito aos motociclistas em Florianópolis, definiu-se como problema central o "Alto número de mortes e feridos graves envolvendo motociclistas em Florianópolis".

Partiu-se, então, para o mapeamento dos atores envolvidos com o problema levantado. Para o início dos trabalhos do GT Motociclistas, em reunião ampliada da Rede Vida no Trânsito do mês de fevereiro de 2014, definiu-se um grupo de trabalho inicial. Posteriormente, já em reunião do GT Motociclistas, estes participantes realizaram um mapeamento de outros atores que poderiam ser agregados ao grupo de trabalho. Como resultado final, os atores mapeados e que passaram a compor o GT Motociclistas foram: Guarda Municipal de Florianópolis; Polícia Militar; Polícia Rodoviária Federal; HONDA, Associação de Motociclistas; CEREST; Via Ciclo; Vigilância em Saúde; SEST/SENAT; Associação dos CFCs; Moto Clubes; FENABRAVE/SC; SAMU; SBOT/SC; Guarda Municipal de São José; DETRAN/CONTRAN; SINTRAUTO/SC e SINTRATURB.

Ao longo das reuniões, entretanto, percebeu-se a dificuldade de envolvimento destes grupos. Ainda que os trabalhos tenham continuado sem o envolvimento de grande parte deles, identificou-se a necessidade, não preenchida pela metodologia, de uma ferramenta que auxiliasse no desenvolvimento de uma estratégia de comunicação, ou seja, do repasse das informações a esses stakeholders.

Passou-se, a seguir, para a definição do objetivo geral proposto pelo programa, ou seja, o foco do programa. Tendo em vista o papel assumido pelo GT Motociclistas, delimitou-se como objetivo geral "Reduzir 
progressivamente o número de mortes e feridos graves envolvendo motociclistas em Florianópolis". Para o objetivo geral, conforme previsto pela metodologia proposta, foi estabelecido um indicador de impacto para monitoramento: MFG (mortos mais feridos graves há '30 dias') por 100.000 habitantes. A meta, por sua vez, seria delimitada apenas quando estivesse finalizada a análise dos dados sobre a situação atual do número de mortes e feridos graves envolvendo motociclistas em Florianópolis, a qual, no momento da realização da fase de teste/validação, estava sendo realizada pelo Grupo de Informação. No que diz respeito ao meio de verificação, definiu-se que os dados para subsidiar o acompanhamento da taxa estabelecida como indicador seriam fornecidos pelo Grupo de Informação, que ao analisar os casos de mortes e feridos graves em acidentes de trânsito de uma forma geral, já identificam os números relacionados aos casos que envolvem motociclistas.

A segunda subdivisão da primeira etapa, denominada Compreensão do Problema, tem início com a análise de causas e efeitos do problema central delimitado anteriormente. Para isso, seguindo a sugestão de Hollins e Hollins (1991), os membros do GT Motociclistas foram divididos em dois grupos.

Conforme previsto na metodologia, foram delimitadas as causas e efeitos, tanto imediatos quanto os subsequentes, do problema central. As causas foram dispostas paralelamente, por baixo do problema. De forma similar, os efeitos foram dispostos paralelamente, por cima dele. A partir da reflexão inicial de causas e efeitos feita nos grupos focais, a discussão foi trazida para o grande grupo, de modo que as informações apresentadas por cada grupo fossem novamente aprimoradas e o conhecimento de cada um fosse utilizado para a criação de uma única análise de causa e efeito.

Após a finalização da análise de causa e efeito, partiu-se para o desenvolvimento da Árvore de Problemas, que apresenta apenas as causas que contribuem de forma significativa para a existência do problema central, sobre as quais a proposição de ações demonstra potencial para a solução. Com base na Árvore de Problemas, foram selecionadas apenas as causas críticas em que o GT Motociclistas possuísse os recursos necessários para atuar.O critério de seleção foi a governabilidade, considerando-se tanto o grupo de trabalho como um todo, quanto a governabilidade por parte de determinada instituição membro do GT Motociclistas que, mesmo de forma isolada, apresentava controle sobre os recursos principais.

As causas selecionadas foram: inadequação viária; sinalização inadequada; inadequação da velocidade da via; falta de manutenção das vias; condição inadequada da pessoa; condução inadequada por parte dos motociclistas e por parte dos outros condutores; ausência de direção defensiva; imprudência; sistema de trabalho; falha na fiscalização; consumo de substâncias psicoativas; condição do veículo; má conservação/ manutenção do veículo e falta de prioridade para o tema trânsito.

Finalizando a primeira etapa, foram delimitados os indicadores intermediários, tendo como base as causas e efeitos governáveis construídos pelo GT Motociclistas. Para isso, foram estabelecidas cinco grandes áreas: (1) Prioridade com o tema trânsito; (2) Fiscalização; (3) Inadequação viária; (4) Condução inadequada e (5) Condição do veículo. Com base nelas, os indicadores delimitados foram: estrutura organizacional dos órgãos municipais envolvidos com a temática do trânsito; número de blitz e autuações; taxa de mortes e feridos graves entre motociclistas em virtude de sinalização inadequada; taxa de mortes e feridos graves entre motociclistas em virtude da ausência de direção defensiva; taxa de mortes e feridos graves entre motociclistas em virtude de imprudência; taxa de mortes e feridos graves em virtude da falta de conservação/manutenção do veículo. Os meios de verificação selecionados foram: legislação que dispõe sobre a estrutura organizacional, informações dos órgãos competentes pelas blitz e autuações e dados das análises do grupo de informação.

\subsection{Prospecção, Geração e Filtro de Soluções}

A primeira subdivisão da segunda etapa tem início com a identificação dos serviços/projetos que trabalham ou já trabalharam com os problemas identificados e suas causas na região onde o programa se encontra inserido.

No que diz respeito à Inadequação Viária, foram selecionadas as causas "sinalização inadequada" e "falta de manutenção das vias". Os membros da equipe do GT Motociclistas decidiram não trabalhar com a causa "inadequação da velocidade da via", tendo em vista o fato de já existir o GT Velocidade, que tem como objetivo analisar a problemática da velocidade relacionada ao número de mortes e feridos graves no trânsito em Florianópolis. Para a "sinalização inadequada" e "falta de manutenção das vias" foram mapeados os seguintes serviços/projetos existentes: Ações do IPUF, DNIT e DEINFRA; Sinalização temporária pela Guarda Municipal, PM, PMRV e PRF; Manutenção pela Secretaria de Obras de Florianópolis, DEINFRA e DNIT.

Já em relação à Condição Inadequada da Pessoa, foram selecionadas as seguintes causas: "falha na fiscalização", que consiste em um dos fatores relacionados à imprudência por parte do motociclista e, consequentemente, uma condução inadequada; "ausência de direção defensiva" e "sistema de trabalho". Aqui, da mesma forma como já mencionado acima, decidiu-se não trabalhar com o "consumo de substâncias psicoativas", embora essa apareça como uma das causas da imprudência por parte dos motociclistas, em 
virtude de já existir o GT Beber e Dirigir, que tem como objetivo analisar a problemática do consumo de substâncias psicoativas, entre elas o álcool, relacionado ao número de mortes e feridos graves no trânsito em Florianópolis. Para as causas selecionadas, foram mapeados os seguintes serviços/projetos existentes: policiamento ostensivo e blitz pela Guarda Municipal, PM, PMRV e PRF; vídeo monitoramento da PM; pardais, lombadas eletrônicas e multas; radares móveis; cursos do SEST-SENAT; curso de direção defensiva para agentes de segurança; curso para CNH; Resolução no 168 do CONTRAN; Cursos oferecidos por instituições privadas; Lei no 12.619; Resolução n 350 e 356 do CONTRAN; Lei Municipal no 9.503/2012.

Por fim, no que diz respeito à Condição Inadequada do Veículo foi selecionada como causa a "má conservação/manutenção do veículo". Para esta, foram mapeados os serviços/projetos existentes que seguem: fiscalização pelos agentes de segurança, manutenção pelos proprietários, inspeção veicular pelo DETRAN.

Posteriormente, embora a metodologia traga como proposta a identificação de boas práticas relacionadas à problemática, não foram encontradas, pelo GT Motociclistas, boas práticas de serviços/projetos relacionadas às causas analisadas.

Foram, então, analisados os pontos fortes e fracos dos serviços/projetos identificados. Em virtude de os atores do GT Motociclistas não serem membros da maior parte das instituições prestadoras destes serviços, decidiu-se estabelecer como ponto forte apenas a existência do serviço. Entendeu-se que a existência e prestação em si de um serviço/projeto focado na solução das causas do problema central, seria um ponto forte, tendo em vista que, pela visão de usuários, os mesmos eram efetivos em sua prestação pontual. Todavia, assim como na maior parte dos casos, os serviços analisados possuíam pontos fracos, que, de acordo com a visão de usuários dos serviços, podiam ser listados e para os quais poderiam ser propostas melhorias.

Para os serviços/projetos mapeados relacionados à sinalização inadequada foram estabelecidos os pontos fracos que seguem: demora para a reposição de placas de sinalização; não observância das resoluções do CONTRAN e do CTB na sinalização das vias; falta de sinalização; depredação da sinalização ou furto; falta de sinalização complementar relacionada à pista escorregadia em trechos de risco; obstrução da sinalização e falta de intervalo entre a abertura de um sinal e o fechamento de outro. Para os serviços/projetos relacionados à falta de manutenção das vias foram listados os seguintes pontos fracos: demora entre o aparecimento de um problema e a solução do mesmo, deficiência na qualidade de pavimentação, baixa qualidade do processo de pavimentação. Já para os serviços/projetos relacionados à ausência de direção defensiva foram listados como pontos fracos: baixa qualidade na formação dos condutores, pouca quantidade de cursos de direção defensiva. No que diz respeito aos serviços/projetos relacionados ao sistema de trabalho foram estabelecidos os seguintes pontos fracos: fiscalização falha da aplicação da legislação e dificuldade de implementação da legislação por problemas com o DETRAN. Por fim, para os serviços/projetos mapeados relacionados à má conservação/manutenção do veículo foram listados os seguintes pontos fracos: fragilidade da fiscalização, falta de consciência do proprietário e falha na inspeção veicular.

Finalizado o momento da Prospecção de Soluções, passou-se para a Geração de Soluções. Esta última é composta por dois momentos: (1) a identificação de como os serviços existentes podem ser melhorados e (2) a identificação de novos serviços ou ações que podem ser criados.

O GT Motociclistas, antes de propor as melhorias e os novos serviços, optou por tentar envolver os atores/ instituições que eram responsáveis, naquele momento, pela execução dos serviços mapeados, de modo que os mesmos participassem do processo de criação. Entretanto, em reunião com umas das instituições responsáveis pela Infraestrutura Viária em Florianópolis, no dia 11 de abril de 2014, os membros da equipe do GT Motociclistas perceberam que antes de desenvolver uma parceria com essas instituições para o desenvolvimento de soluções aos problemas identificados, era preciso sensibilizar as mesmas acerca da existência destes e, principalmente, acerca da necessidade de trabalhar sobre estes problemas. Diante disso, decidiram pela geração de soluções voltadas à sensibilização dos atores/instituições e fomento ao trabalho conjunto, tendo como objetivo a solução do problema central através da minimização da atuação de suas causas principais e com governabilidade. Para a criação destas ações, os membros do GT Motociclistas dividiram, a partir dos resultados da etapa de Delimitação e Compreensão do Problema, três grandes áreas de atuação: Infraestrutura Viária, Fiscalização e Educação/Direção Defensiva. Estas grandes áreas englobavam as causas selecionadas como prioritárias e com governabilidade para atuação.

É válido observar que no momento de divisão das grandes áreas foi percebida a necessidade de uma ferramenta que possibilitasse uma síntese de todas as discussões, especificamente dos principais resultados obtidos até a etapa da Geração de Soluções, de modo a facilitar o trabalho, por parte da equipe, de desenvolvimento de soluções, principalmente no que diz respeito a trazer uma orientação do foco para o qual as ações devem seguir. A falta de uma ferramenta de síntese fez com que a equipe tivesse que retomar todos os resultados das ferramentas utilizadas nas demais etapas, o que significou um dispêndio maior de tempo. Por isso, esse aspecto foi considerado uma oportunidade de melhoria à metodologia proposta. 
Estabelecidas as grandes áreas, os atores do GT Motociclistas decidiram, ainda, pela proposição de ações já viáveis para o momento, tendo em vista que a partir delas deveria ser possível o início do processo de implementação. No que diz respeito à Infraestrutura Viária, as soluções apresentadas foram: georreferenciar o local dos acidentes, realizando a divulgação dos resultados e encaminhando um relatório para os órgãos competentes e o desenvolvimento de um APP para informar sobre buracos e sinalização danificada. Já no que tange à Fiscalização, as soluções propostas foram: sensibilizar os órgãos competentes para a instalação de radares e lombadas eletrônicas; policiamento ostensivo - elaboração de um plano conjunto de fiscalização (imprudência e conversação/manutenção do veículo); sensibilizar o MTE e o MPT para a realização de blitz sistema de trabalho e sensibilizar o SESP para a realização de blitz - mototáxi. Por fim, relacionado à Educação/ Direção Defensiva foi proposto como solução o desenvolvimento de um projeto de educação para direção defensiva, iniciando com um estudo de boas práticas.

Em reunião posterior à geração das soluções, em virtude da presença de novos participantes, foram apresentados os resultados da Árvore de Problemas com governabilidade, bem como as discussões geradas no momento de Prospecção e Geração de Soluções. A partir da apresentação, um dos participantes, representando a Associação de Motociclistas da Grande Florianópolis, chamou a atenção para o baixo número de ocorrências de mortes e feridos graves envolvendo os profissionais motofretistas. Estes estavam ligados à causa "sistema de trabalho" apresentada na Árvore de Problemas. Com base nisso, haviam sido propostas duas ações: (1) Sensibilizar o Ministério do Trabalho e Emprego e o Ministério Público do Trabalho para a realização de blitz e (2) Sensibilizar o SESP para a realização de blitz - mototáxi. Em consulta ao Grupo de Informação, constatou-se que, dos casos analisados até o momento, nenhum tinha relação com o profissional motofretista. Diante disto, as ações relacionadas à causa "sistema de trabalho" foram retiradas das ações propostas inicialmente, embora não tenham sido excluídas de forma definitiva.

Pelas peculiaridades apresentadas no contexto do GT Motociclistas, que resultaram em um número menor de soluções propostas e, consequentemente, na possibilidade de implementação simultânea de todas elas, não se identificou a necessidade de aplicação do Filtro de Soluções. Dessa forma, as soluções propostas foram diretamente encaminhadas para a elaboração do protótipo.

\subsection{Elaboração do Protótipo}

Para a elaboração do protótipo, foram aplicadas as tabelas da ferramenta 5W2H devidamente adaptadas para a prototipagem de serviços. Destaca-se, entretanto, que, até o momento da finalização da fase de teste/ validação, foram elaborados apenas os protótipos das áreas de Infraestrutura Viária e Fiscalização. A não elaboração do protótipo da solução apresentada para a área de Educação/Direção Defensiva se deu em virtude de ainda não se ter de forma concreta a forma como o projeto de educação relacionado à direção defensiva seria estruturado e qual seria o seu foco. Por isso, na fase de Geração de Soluções, especificamente no que diz respeito ao projeto de educação, delimitou-se como ação inicial a busca e estudo de boas práticas relacionadas à mudança de comportamento voltada à direção defensiva, as quais embasariam o foco do projeto de educação e, posteriormente, possibilitariam a elaboração do protótipo.

Ao finalizar os protótipos, percebeu-se que a utilização da ferramenta $5 \mathrm{~W} 2 \mathrm{H}$ não trouxe o detalhamento necessário dos serviços a serem propostos e suas entregas específicas. Assim, ela não levou os membros do GT Motociclistas a explorar a solução proposta e avaliá-la de forma mais detalhada, de forma a evitar erros futuros na implementação ou no momento em que o serviço for repassado para a operação das organizações (BROWN, 2008; SCHRAGE, 2000). Sendo assim, também neste ponto identificou-se uma lacuna/oportunidade de melhoria à metodologia proposta.

\section{PROPOSTA DE INTERVENÇÃO/RECOMENDAÇÃO FINAL}

A partir das lacunas identificadas na fase de teste/validação, foram feitas algumas alterações na proposta de metodologia.

A primeira alteração diz respeito à inserção de um modelo para o desenvolvimento de uma estratégia de comunicação com os stakeholders mapeados na "Delimitação do Problema". O objetivo é possibilitar o engajamento destes atores, ainda que não haja a possibilidade de sua participação direta nos grupos de trabalho. Gavin e Pinder (1998) e Gosling e Edwards (2003) apresentam uma escala voltada ao envolvimento de partes interessadas. Esta escala - seja para informar, consultar, oferecer parceria ou dar o controle da ação a um grupo de partes interessadas - pode ser determinada em função de cada etapa do ciclo de vida de um programa/projeto. Como forma de melhor atender à necessidade identificada na fase de teste/validação, foi feita uma adaptação da escala proposta por Gavin e Pinder (1998) e Gosling e Edwards (2003). Tendo em vista que o objetivo da inserção da ferramenta na metodologia consiste no desenvolvimento da comunicação e 
engajamento da totalidade dos stakeholders ao longo do Design e Implementação, as fases do ciclo de vida de um projeto foram substituídas pelas etapas da própria metodologia desenvolvida, gerando, assim, melhor adequação à proposta.

A segunda alteração diz respeito à inserção de uma ferramenta, anterior ao momento de "Geração de Soluções", voltada ao desenvolvimento de uma síntese das discussões feitas pelo grupo de trabalho. Essa medida visa a orientar a proposição das ações que irão compor o programa, de modo que estas estejam dentro dos objetivos, tanto geral quanto específicos. Como ferramenta, adotou-se o Modelo Lógico (CASSIOLATO; GUERESI, 2010). Os autores destacam que esta é uma forma sistemática e visual de apresentar e compartilhar a compreensão das relações existentes entre os recursos disponíveis para as ações a serem propostas e os resultados que se espera alcançar, gerando um encadeamento lógico. Como forma de melhor atender as necessidades identificadas na fase de teste/validação da metodologia junto ao GT Motociclistas, foi feita uma adaptação do modelo proposto por Cassiolato e Gueresi (2010), sendo o modelo final composto pelos seguintes itens: problema central, grandes áreas, causas, ações, produtos, resultados intermediários, resultados finais e impactos.

A terceira e última alteração diz respeito à substituição da ferramenta $5 \mathrm{~W} 2 \mathrm{H}$, inicialmente adotada para a etapa de "Elaboração do Protótipo", por outra ferramenta que apresente maior nível de detalhamento das informações. Espera-se que o protótipo retrate, de fato, a experiência a ser desenvolvida com a proposição do serviço. Pelo nível de detalhamento apresentado, optou-se pela ferramenta Business Model Generation - CANVAS (OSTERWALDER; PIGNEUR, 2010). Embora a ferramenta, em seu modelo original, apresente um foco no desenvolvimento de um plano de negócios, especialmente na área empresarial, a mesma se destaca pela integração dos requisitos, de forma a exercitar a inter-relação de cada atividade na prestação do serviço da organização. A ferramenta adaptada apresenta 9 itens: segmentação de usuários, proposição de valor, canais de distribuição, relacionamento com os usuários, recursos críticos, atividades críticas, parceiros, custos e fontes de receita.

\section{CONSIDERAÇÕES FINAIS}

Frente ao desafio posto aos gestores públicos para a conquista de maior efetividade nos serviços ofertados ao cidadão a partir da identificação de suas reais necessidades, este trabalho teve como objetivo a proposição de uma metodologia para o design e a implantação de serviços públicos efetivos na Prefeitura Municipal de Florianópolis, a partir dos pressupostos conceituais do Design de Serviços e do Gerenciamento de Projetos. Especificamente, o estudo foi desenvolvido com foco em uma situação-problema identificada na Rede Vida no Trânsito.

A metodologia proposta como resultado do estudo, caracterizado como uma pesquisa-ação, tomou como base as grandes áreas do Design de Serviços e foi dividida em seis etapas: (1) Delimitação e Compreensão do Problema; (2) Prospecção, Geração e Filtro de Soluções; (3) Elaboração do Protótipo; (4) Concepção e Implementação do Projeto; (5) Monitoramento e Avaliação e (6) Redesign.

Além de relatar a situação problema que originou a pesquisa, apresentar o diagnóstico e descrever o processo de concepção da metodologia proposta, este artigo relatou, também, o processo de teste/validação da metodologia, no qual foram identificadas limitações que suscitaram a necessidade de ajustes. Nesse sentido, na etapa final da pesquisa foram incorporadas, na metodologia, três ferramentas: Técnica de Gerenciamento de Stakeholders, Modelo Lógico e CANVAS. Com exceção do Modelo Lógico, estas ferramentas não passaram pela fase de teste/validação e, portanto, não há evidências de que se configuram como as melhores opções para os problemas identificados. Nesse sentido, há, nesse ponto, oportunidade para pesquisas futuras.

O trabalho procura trazer contribuições no campo teórico, ao aliar áreas de conhecimento distintas: o Novo Serviço Público (DENHARDT; DENHARDT, 2000), a Nova Governança Pública (BEVIR, 2009; KISSLER; HEIDEMANN, 2006), o Design de Serviços (HOLLINS; HOLLINS, 1991; VAN DIJK; RAIJMAKERS; KELLY, 2010; BROWN, 2008) e o Gerenciamento de Projetos (BOLAY, 1993; ARMANI, 2004; PMI, 2008). Dada a carência por mecanismos de implementação às já bem consolidadas bases teóricas do Novo Serviço Público e da Nova Governança Pública, este trabalho, de natureza tecnológica, ajuda a preencher lacunas ainda existentes nesse campo.

Além da contribuição teórica, é possível citar contribuições práticas. A fase de teste/validação, além de possibilitar o aprimoramento da metodologia proposta, auxiliou a Rede Vida no Trânsito, mais diretamente o GT Motociclistas, no design de um programa com seus respectivos serviços e produtos, seguindo, assim, as metas apresentadas pelo Ministério de Saúde. Além disso, o GT Velocidade também iniciou o design de um programa utilizando a metodologia proposta, tendo como base o aprendizado trazido pela aplicação realizada no GT Motociclistas. Entretanto, é válido notar que a utilização da metodologia proposta pelo GT Velocidade ocorreu de forma independente, ou seja, foi conduzida pelos próprios membros da Rede Vida no Trânsito.

Cumpre observar também que, embora não contemplado pela fase de teste/validação, após a finalização deste trabalho o GT Motociclistas deu início ao desenvolvimento dos projetos e à implementação dos serviços criados com base na metodologia. Neste sentido, destaca-se, dentre as sugestões para estudos futuros, a 
avaliação do uso da metodologia como um todo, de forma que se possa mensurar sua contribuição, de fato, para o alcance da efetividade dos serviços desenvolvidos.

Ainda, sugere-se o desenvolvimento de pesquisas relacionadas à propriedade intelectual dos produtos que venham a ser desenvolvidos de forma conjunta com os serviços apresentados, principalmente para os casos em que a criação for realizada por um conjunto de parceiros. Novas fases e/ou instrumentos podem ser incorporados na metodologia vislumbrando questões desta natureza.

Por fim, sugere-se que metodologia seja expandida aos demais municípios brasileiros que desenvolvem o Projeto Vida no Trânsito, principalmente àqueles que também trabalham sob a ótica da Estratégia de Proatividade e Parceria (CARDITA; DI PIETRO, 2010), tendo em vista a compatibilidade identificada entre as metodologias. Além disso, sugere-se investigar a possibilidade de uso da metodologia em outros setores e problemáticas da Administração Pública, uma vez que sua estrutura, embora tenha sido desenvolvida com base na problemática relacionada ao trânsito, não se restringe a esta.

\title{
PURSUING EFFECTIVENESS IN PUBLIC ADMINISTRATION: A PROPOSAL FOR A METHOD TO DESIGN AND IMPLEMENT PUBLIC SERVICES IN THE CITY OF FLORIANÓPOLIS.
}

\begin{abstract}
The approach of the New Public Service and, more recently, the New Public Governance, draw attention to the importance of the effectiveness of services, emphasizing the focus on citizen and the co-production of public goods as means to achieving it. However, the proposition of effective public services has been a challenge for many organizations and levels of government. The study context, in Florianópolis, is the "Life in Traffic Project", linked to Road Safety in 10 Countries Project, conducted by an international consortium of partners. The study was characterized as Action Research. It made use of data collection, documentary survey, participant observation and daily action research. The result is the proposal of a methodology that aims to support the process of design and implementation of more effective municipal services with intense involvement of stakeholders. Validated in the field and described in detail in the article, the methodology consists of six steps: Problem Delimitation and Understanding; Solution Prospection, Generation and Filtering; Prototype Preparation; Design and Implementation of the Project; Monitoring and Evaluation; and Redesign. Besides the impact generated in the local results of the project, it is expected that it can be adopted in other departments of the Florianópolis City Hall and in other municipalities participating in the Life in Traffic Project. In addition, the research seeks to contribute to the theoretical advance of a field that combines foundations of the New Public Service, Service Design and Project Management.
\end{abstract}

Keywords: Effectiveness. New Public Service. Service Design. Public Projects. Life in Traffic Project. 


\section{REFERÊNCIAS}

ANSELL, C.; TORFING, J. Public innovation through collaboration and design. New York: Routledge, 2014.

ARMANI, D. Como elaborar Projetos? Guia Prático para Elaboração e Gestão de Projetos Sociais. Porto Alegre: Tomo Editorial, 2004.

BEVIR, M. Key Concepts of Governance. London: Sage, 2009

BOLAY, F. W. Planejamento de Projeto Orientado por Objetivos: método ZOPP. Recife: GTZ, 1993.

BRASIL.Vigitel Brasil 2012: vigilância de fatores de risco e proteção para doenças crônicas por inquérito telefônico. Brasília: Ministério da Saúde, 2013.

BROWN, T. Design Thinking. Rio de Janeiro: Campus, 2008.

CARDITA, J.; DI PIETRO, G. Estratégia de Proatividade e Parceria: Um modelo de participação comunitária para abodar a segurança no trânsito. Switzerland: Global Road Safety Partnership, 2010.

CASSIOLATO, M; GUERESI, S. Como elaborar um modelo lógico: roteiro para formular programas e organizar avaliação. Brasília: IPEA, 2010. (Nota Técnica)

COHEN, Ernesto; FRANCO, Rolando. Avaliação de projetos sociais. Petrópolis: Vozes, 2008.

COTTA, Tereza Cristina. Metodologias de avaliação de programas e projetos sociais: análise de resultados e de impacto. Revista do Serviço Público, Brasília, ano 49, n. 2, p. 103-124, abr./jun. 1998.

DAYCHOUM, M. 40 + 8 Ferramentas e Técnicas de Gerenciamento. 4. ed. Rio de Janeiro: Brasport, 2010.

DENHARDT, R.; DENHARDT, J. The New Public Service: Serving rather than Steering. Public Administration Review, [s.I], v. 60, p. 549-559, 2000.

DOLOI, H. K. Understanding stakeholders' perspective of cost estimation in project management. International Journal of Project Management, [s.l], v. 29, p. 622-636, 2011.

EUROPEAN COMISSION. Good Practices for including principles of ex ante evaluation in the design of cooperation projects and programs. Europe: Aid Cooperation Office, 2005.

GAVIN, T.;PINDER, C. Impact assessment stakeholder analysis. Manchester: EDIAIS, University of Manchester, 1998. Disponível em: <http://www.enterpriseimpact.org.uk/pdf/StakeholderAnalysis.pdf >. Acesso em: 20 ago. 2014.

GIDO, J.; CLEMENTS, J. P. Gestão de Projetos. 3. ed. São Paulo: Thomson, 2007.

GODOY, A. Estudo de caso qualitativo. In: GODOI, C. K.; BANDEIRA-DE-MELLO, R.; SILVA, A. B. (Org.). Pesquisa qualitativa em organizações. São Paulo: Saraiva, 2006. p. 115-146.

GOSLING, L; EDWARDS, M. Toolkits: a practical guide to planning, monitoring, evaluation and impact assessment. London: Save the Children, 2003.

HOLLINS, B; HOLLINS, G. Total Design: Managing the design process in the service sector. London: Pitman Publishing, 1991.

HOOD, C. A Public Management for all seasons. Public Administration Review, [s.l.], v. 68, p. 3-19, 1991.

IIDA, I. Planejamento estratégico situacional. Prod., São Paulo, v. 3, n. 2, p. 113-125, dez. 1993. Disponível em $<$ http://www.scielo.br/scielo.php?script=sci_arttext\&pid=S0103-65131993000200004\&lng=en\&nrm=iso >. Acesso em: 25 abr. 2014. 
JACKSON, P. The new public sector management: surrogate competition and contracting out. In JACKSON, P.; PRICE, C. (Ed.). Privatization and regulation: A review of the issues. New York: Longman, 1994. p. 120-148.

KELLOGG FOUNDATION. W. K. Kellog Foundation Evaluation Handbook. Philosophy and Expectations. Battle Creek: Kellogg Foundation, 1998.

KISSLER, L; HEIDEMANN, F.G. Governança pública: novo modelo regulatório para as relações entre Estado, mercado e sociedade? Revista da Administração Pública, Rio de Janeiro, v. 40, n. 3, p. 479-499, 2006.

LEININGER, M. M. Nature, rationale and importance of qualitative research methods in nursing. In: LEININGER, M. M. (Ed.). Qualitative research methods in nursing. New York: Grune\&Stratton, 1985. p. 1-25.

LOCKWOOD, T. (Ed.). Design thinking: Integrating innovation, customer experience, and brand value. New York: Allworth Press, 2010.

MENEZES, L. C. M. Gestão de Projetos. 3. ed. São Paulo: Atlas, 2009.

MORITZ, S. Service Design: practical access to an evolving field. London: Köln International School of Design, University of Applied Sciences Cologne, 2005.

MOZOTA, B. B. de. Design Management: Using Design to Build Brand Value and Corporate Innovation. New York: Allworth Press, 2003.

OLIVEIRA, S. T. Ferramentas para o aprimoramento da qualidade. 2. ed. São Paulo: Pioneira, 1996.

OSBORNE, S. P.; RADNOR, Z.; NASI, G. A. New Theory for Public Service Management? Toward a (Public) ServiceDominant Approach. The American Review of Public Administration, Orlando, n. 43, p. 135-158, 2013.

OSTERWALDER, A.; PIGNEUR, Y. Business model generation. John Wiley \& Sons: New Jersey, 2010.

PEDEN, M. et al. World Report on Road Traffic Injury Prevention. Geneva: World Health Organization, 2004.

POLLITT, C. Manageralism and the Public Services: the Anglo-American Experience. Oxford: Basil Blackwell, 1990.

PROJECT MANAGEMENT INSTITUTE (PMI). Um guia do conjunto de conhecimento em gerenciamento de projetos (Guia PMBOK). 4. ed. Pennsylvania: PMI, 2008.

SCHRAGE, M. Serious play: how the world's best companies simulate to innovate. Boston: Harvard Business Press, 2000.

SCOTT, W. R. Organizations: rational, natural and open system. 5. ed. New Jersey: Prentice Hall, 2003.

SIODMOK, A. A hotbed of creativity. In:THOMAS, Emily (Ed). Innovation by design in public services. Londres: SOLACE Foundation Imprint (SFI), 2008. p. 34-39.

SUNDERLAND CITY COUNCIL. Make it work: Northern Way Worklessness Pilot: Project Review, 2008.

TULIP, A. Planning project costs. Butterworth \& Co (Publishers) Ltd., Belfast, v.1, n. 4, p. 194-196, 1983.

UNICEF. A UNICEF Guide for Monitoring and Evaluating. Making a Difference? [20--?]. Disponível em: <http:// preval.org/documentos/00473.pdf>. Acesso em: 17 fev. 2014.

VAN DIJK, G.; RAIJMAKERS, B.; KELLY, L. This is service design thinking. Amsterdam: Bis Publishers, 2010. 
WAISELFISZ, J. J. Mapa da violência 2013: acidentes de trânsito e motocicletas.Rio de Janeiro: CEBELA: FLACSO, 2013. Disponível em: <http://www.mapadaviolencia.org.br/pdf2013/mapa2013_transito.pdf>. Acesso em: 27 maio 2014.

WHOLEY, Joseph; HATRY, Harry; NEWCOMER, Kathryn E. Handbook of practical program evaluation. San Francisco: Jossey Bass, 2004. 